\title{
Pengaruh Motivasi terhadap Perilaku Kerja Petani Karet di Desa Puain Kanan Kecamatan Tanta Kabupaten Tabalong
}

\section{(Motivation Effect on Working Behavior of Rubber Farmers in Puain Kanan Village Tanta District Tabalong Regency)}

\author{
Azwar Saihani' ${ }^{1)}$ \& Siti Izzatil Sa'ira ${ }^{2)}$ \\ Program Studi Agribisnis, Sekolah Tinggi Ilmu Pertanian Amuntai \\ 1)Azwar.saihani63@yahoo.com \\ 2)izzatil@yahoo.com
}

\begin{abstract}
ABSTRAK
Penelitian ini bertujuan untuk mengetahui pengaruh motivasi terhadap perilaku kerja petani karet, mengetahui motivasi dominan petani karet, mengetahui hubungan positi atau negatif dan persentase pengaruh motivasi terhadap perilaku kerja petani karet di Desa Puain Kanan Kecamatan Tanta Kabupaten Tabalong. Metode penelitian yang digunakan metode studi kasus dengan metode pengumpulan data yaitu metode wawancara. Pengumpulan data dilakukan dari bulan Mei sampai Agustus. Analisis yang digunakan adalah analisis kualitatif tentang perilaku kerja petani karet, motivasi kekuasaan, motivasi afiliasi dan motivasi prestasi. Analisis kuantitatif menggunakan analisis regresi berganda dengan pengujian secara simultan, pengujian secara parsial, koefisien korelasi dan koefisien determinasi menggunakan sofware SPSS 23 for windows. Hasil penelitian yang diperoleh menunjukkan bahwa motivasi memberikan pengaruh terhadap perilaku kerja petani karet dengan nilai Fhitung 12, 470. Variabel motivasi prestasi merupakan motivasi terbesar yang memberikan pengaruh terhadap perilaku kerja petani karet dengan nilai thitung tertinggi sebesar 3,005. Motivasi kekuasaan, motivasi afiliasi dan motivasi prestasi memiliki hubungan positif terhadap perilaku kerja petani karet dengan nilai kontribusi variabel motivasi sebesar $51 \%$.
\end{abstract}

Kata Kunci : Perilaku, petani, karet, motivasi, kerja.

\section{ABSTRACT}

This study aims to determine the effect of motivation on working behavior of rubber farmers, knowing the dominant motivation of rubber farmers, knowing the positive or negative relationship and the percentage of the influence of motivation on the working behavior of rubber farmers in the Puain Kanan Village, Tanta District, Tabalong Regency. The research method used is the case study method with data collection methods, namely the interview method. Data collection is carried out from May to August. The analysis used was qualitative analysis of rubber farmer's work behavior, power motivation, affiliate motivation and achievement motivation. Quantitative analysis uses multiple regression analysis with simultaneous testing, partial testing, correlation coefficient and coefficient of determination using SPSS 23 software for Windows. The results obtained showed that motivation influenced the working behavior of rubber farmers with $F_{\text {count }} 12,470$. Performance motivation variables were the biggest motivations that influenced the working behavior of rubber farmers with the highest $t_{\text {count }}$ value of 3.005. Motivation of power, affiliation motivation and achievement motivation have a positive relationship to the working behavior of rubber farmers with a motivation variable contribution value of $51 \%$.

Keywords : Behavior, farmers, rubber, motivation, work.

\section{PENDAHULUAN}

Kalimantan Selatan khususnya di Kabupaten Tabalong perkebunan mempunyai peranan yang cukup besar dalam pengembangan pertanian. Tanaman perkebunan yang paling potensial di daerah ini adalah karet dengan luas arealnya mencapai 71.189 ha dan kelapa 1.012 ha. Sedangkan produksi perkebunan terbesar adalah komoditi karet dengan 61.235 ton kemudian kelapa sawit 4.640 ton (BPS Kabupaten Tabalong, 2015).

Kebanyakan para petani karet tidak dapat menentukan besarnya pengeluaran, padahal karet memerlukan penanganan yang 
baik untuk menaikkan pendapatan petani. Pengambilan keputusan yang tepat dalam memecahkan permasalahan yang dihadapi merupakan hal yang sangat penting dalam berusahatani khususnya usahatani karet. Sehingga hal ini sangat membutuhkan pengetahuan yang luas dalam berusahatani. Dengan pengetahuan yang ada tentunya belum cukup, sehingga memerlukan keterampilan khusus untuk dapat bertahan dalam usaha tersebut. Namun itu semua ternyata tidak melumpuhkan niat petani karet dalam menjalankan usahanya. Untuk itu perlu pengkajian apakah yang sebenarnya menjadi motivasi kerja dari para petani.

Penelitian ini bertujuan untuk mengetahui (i) pengaruh motivasi terhadap perilaku kerja petani karet di Desa Puain Kanan Kecamatan Tanta Kabupaten Tabalong (ii) motivasi terbesar petani karet dalam menjalankan usahanya (iii) hubungan positif atau negatif dan persentase pengaruh motivasi terhadap perilaku kerja petani karet di Desa Puain Kanan Kecamatan Tanta.

\section{METODE PENELITIAN}

\section{Tempat dan Waktu Penelitian}

Penelitian ini dilaksanakan di Desa Puain Kanan Kecamatan Tanta Kabupaten Tabalong. Waktu penelitian dimulai pada bulan April 2017 - Juli 2017.

\section{Jenis dan Sumber Data}

Jenis dan sumber data menggunakan pendekatan survei yaitu penelitian yang dilakukan pada populasi besar maupun kecil, tetapi data yang dipelajari adalah data dari sampel yang diambil dari populasi tersebut (Siregar, 2013). Data yang digunakan berupa data primer yang diperoleh dari hasil wawancara dari petani dan data sekunder diperoleh dari Penyuluh Pertanian Lapangan (PPL), Badan Pusat Statistik, dan Instansi terkait.

\section{Metode Penarikan Sampel}

Berdasarkan teori, penelitian ini merupakan penelitian dekriptif yaitu penelitian yang dimaksudkan untuk pengukuran yang cermat terhadap fenomena sosial tertentu. Menurut Roscoe dalam buku
Metode Penelitian Bisnis Sugiyono (2012) menyatakan ukuran sampel yang layak dalam penelitian adalah antara 30 sampai dengan 500, jika penelitian akan melakukan analisis dengan multivariate (korelasi atau regresi berganda) maka jumlah anggota sampel minimal 10 kali dari jumlah variabel yang diteliti. Variabel penelitian ini ada 4 (independen dan dependen) jadi jumlah anggota sampel sama dengan $10 \times 4=40$ orang. Dalam pengambilan sampel digunakan teknik probability sampling yakni metode sampling yang setiap anggota populasinya memiliki peluang sama untuk terpilih sebagai sampel dengan teknik sampel random sederhana (simple random sampling) (Siregar, 2013).

\section{Analisis Data}

\section{Uji Keampuhan Instrumen}

Menurut Tika (2006) uji keampuhan instrumen dimaksudkan untuk mendapatkan gambaran tentang validitas dan reliabilitas angket yang digunakan.

a. Uji Validitas

Validitas adalah kebenaran dan keabsahan instrumen penelitian yang digunakan. Setiap penelitian selalu dipertanyakan mengenai validitas alat yang digunakan. Suatu alat pengukur dikatakan valid jika alat itu dipakai untuk mengukur sesuatu sesuai dengan kegunaannya. Untuk menghitung validitas digunakan rumus korelasi product moment Karel Pearson yang rumusnya sebagai berikut :

$$
r=\frac{N(\Sigma X Y-(\Sigma X \Sigma Y)}{\sqrt{\left[N \Sigma X^{2}-(\Sigma X)^{2}\right]\left[N \Sigma Y^{2}-(\Sigma Y)^{2}\right.}}
$$

Di mana :

$\mathrm{r}=$ koefisien korelasi

$\mathrm{X}=$ skor pertanyaaan

$\mathrm{N}=$ jumlah observasi/responden

$\mathrm{Y}=$ skor total

b. Uji Reliabilitas

Menurut Siregar (2013) reliabilitas adalah untuk mengetahui sejauh mana hasil pengukuran tetap konsisten, apabila dilakukan pengukuran dua kali atau lebih terhadap gejala yang sama dengan menggunakan alat pengukur yang sama pula. Metode Alpha Cronbach digunakan untuk mengitung reliabilitas suatu tes yang tidak mempunyai pilihan 'benar' atau 'salah' 
maupun 'ya' atau 'tidak', melainkan digunakan untuk menghitung reliabilitas suatu tes yang mengukur sikap atau perilaku. Yang rumusnya sebagai berikut:

1). Menentukan nilai varians setiap butir pertanyaan

$$
\sigma^{2}{ }_{i}=\frac{\Sigma X_{i}^{2}-\frac{\left(\Sigma X_{i}\right)^{2}}{n}}{n}
$$

2). Menentukan nilai varians total

$$
\sigma^{2}{ }_{t}=\frac{\Sigma X^{2}-\frac{(\Sigma X)^{2}}{n}}{n}
$$

3). Menentukan reliabilitas instrumen

$$
r_{11=\frac{|K|}{|k-1|} \mid}\left|1-\frac{\Sigma \sigma^{2} b}{\sigma^{2} t}\right|
$$

Di mana :

$$
\begin{aligned}
& \mathrm{n} \quad=\text { jumlah sampel } \\
& \mathrm{X}_{\mathrm{i}} \quad=\text { jawaban responden }
\end{aligned}
$$

untuk setiap butir pertanyaan

$\Sigma X=$ total jawaban responden untuk setiap butir pertanyaan

$$
\begin{array}{ll}
r_{11} & =\text { reliabilitas instrumen } \\
\mathrm{k} & =\text { banyaknya butir pertanyaan } \\
\Sigma \sigma^{2}{ }_{b} & =\text { jumlah varians butir } \\
& \text { instrumen } \\
\sigma^{2}{ }_{t} & =\text { varians total instrumen }
\end{array}
$$

\section{Uji Hipotesis}

Pada pada penelitian ini terdapat hipotesis sebagai berikut:

$\mathrm{H}_{0}=$ Tidak terdapat pengaruh motivasi terhadap perilaku kerja petani karet

$\mathrm{Ha}=$ Terdapat pengaruh motivasi terhadap perilaku kerja petani karet.

\section{Analisis Regresi Berganda}

Menurut Suliyanto (2011) analisis regresi berganda adalah salah satu analisis statistik yang digunakan untuk mendistribusikan hubungan fungsional anatara variabel bebas dan variabel terikat. Adapun rumus regresi berganda sebagai berikut:

$$
\begin{gathered}
Y=a+b_{1} X_{1}+b_{2} X_{2}+b_{3} X_{3} \\
+e i
\end{gathered}
$$

Dimana:

$$
\begin{array}{ll}
\mathrm{Y} & =\text { variabel terikat } \\
\mathrm{A} & =\text { bilangan konstanta } \\
b_{1} b_{2} b_{3} & =\text { koefisien }- \text { koefisien regresi } \\
\mathrm{X}_{1} \mathrm{X}_{2} \mathrm{X}_{3} & =\text { variabel bebas }
\end{array}
$$

ei diteliti/standar error

= variabel lain yang tidak

Dengan variabel yang akan diteliti yaitu:

1. Variabel terikat atau dependent variable (Y)

Variabel terikat atau dependent variable (Y) diukur melalui perilaku kerja dari petani karet.

2. Variabel bebas atau independet variable

(X)

Motivasi kekuasaan $\left(\mathrm{X}_{1}\right)$, diukur melalui penentuan arah pelaksanaan kegiatan, pengembangan usaha dan keinginan dalam mempegaruhi petani lain atau menjadi pengurus dalam usaha kelompok tani.

Motivasi afiliasi $\left(\mathrm{X}_{2}\right)$, diukur melalui pekerjaan, informasi yang didapat atau diterima, kondisi lingkungan dan pekerjaan yang dilakukan sendiri atau bersama dalam usahatani.

Motivasi prestasi $\left(\mathrm{X}_{3}\right)$, diukur melalui tingkat kemajuan hidup, teknik dan prestasi atau penghargaan yang diperoleh dalam usahatani.

a. Pengujian Secara Simultan

Pengujian secara simultan dilakukan untuk menjawab tujuan pertama penelitian menggunakan uji F. Uji $\mathrm{F}$ dipakai untuk melihat pengaruh variabel independen secara bersama sama atau simultan terhadap variabel dependen dengan menganggap variabel lain bersifat konstan.

Rumus untuk menentukan $F_{\text {hitung }}$ adalah:

$$
F_{\text {hitung }}=\frac{R^{2} /(k-1)}{1-R^{2} /(n-k)}
$$

Di mana;

$$
\begin{aligned}
& \mathrm{R}^{2} \quad=\text { koefisien determinasi } \\
& \mathrm{k}=\text { jumlah variabel } \\
& \mathrm{n}=\text { jumlah pengamatan (ukuran } \\
& \text { sampel) }
\end{aligned}
$$

b. Pengujian secara parsial

Uji parsial dilakukan untuk menjawab tujuan kedua penelitian menggunakan statistik uji $\mathrm{t}$ yaitu untuk menguji apakah variabel bebas memiliki pengaruh yang berarti terhadap variabel terikatnya atau tidak. Rumus untuk menentukan $t_{\text {hitung }}$ adalah: 


$$
t_{\text {hitung }}=\frac{b j}{\mathrm{Sbj}}
$$

Di mana :

$$
\begin{aligned}
\quad t_{\text {hitung }} & =\text { nilai } \mathrm{t} \text { hitung } \\
\text { sbj } & =\text { kesalahan baku koefisien } \\
\text { regresi } &
\end{aligned}
$$$$
\text { bj = koefisien regresi }
$$

c. Koefisien Korelasi dan Koefisien Determinasi

Koefisien korelasi dan koefisien determinasi lakukan untuk menjawab tujuan ketiga penelitian. Menurut Siregar (2013) koefisien korelasi adalah bilangan yang menyatakan kekuatan hubungan antara dua variabel atau lebih atau juga dapat menentukan arah dari kedua variabel. Nilai korelasi $(\mathrm{r})=(-1 \leq 0 \leq 1)$, untuk kekuatan hubungan nilai koefisien korelasi berada di antara -1 dan 1, sedangkan untuk arah dinyatakan dalam bentuk positif (+) dan negatif (-). Rumus koefisien korelasi menggunakan korelasi Pearson Product Moment yaitu untuk mencari arah dan kekuatan hubungan antara variabel bebas (X) dengan variabel terikat (Y). Rumus koefisien korelasi dapat dinyatakan sebagai berikut:

$$
\begin{aligned}
& r=\frac{N(\Sigma X Y-(\Sigma X \Sigma Y)}{\sqrt{\left[N \Sigma X^{2}-(\Sigma X)^{2}\right]\left[N \Sigma Y^{2}-(\Sigma Y)^{2}\right.}} \\
& \quad \text { Di mana : } \\
& \quad r=\text { koefisien korelasi }
\end{aligned}
$$

$\mathrm{X}=$ variabel bebas

$\mathrm{N}=$ jumlah observasi/responden $\mathrm{Y}=$ variabel terikat

Koefisien determinasi adalah angka yang menyatakan atau digunakan untuk mengetahui kontribusi atau sumbangan yang diberikan oleh sebuah variabel bebas (X) atau lebih terhadap variabel terikat (Y). Rumus koefisien determinasi sebagai berikut:

$$
\mathrm{R}^{2}=(\mathrm{r})^{2} \times 100 \%
$$

Di mana:

$\mathrm{R}^{2}=$ koefisen determinasi

$\mathrm{r}=$ koefisien korelasi

Pengolahan data pada penelitian ini seluruhnya akan menggunakan program komputer Statictical Package for Social Science (SPSS) 23 for windows.

\section{HASIL DAN PEMBAHASAN}

\section{Uji Keampuhan Instrumen}

\section{Hasil}

Tabel 1. Hasil pengujian validitas kuesioner penelitian

\begin{tabular}{cccccc}
\hline No. & Variabel & Indikator & r hitung & r tabel & Keterangan \\
\hline 1. & Perilaku Kerja & 1 & 0,388 & 0,312 & Valid \\
& & 2 & 0,451 & 0,312 & Valid \\
& & 3 & 0,388 & 0,312 & Valid \\
& & 5 & 0,606 & 0,312 & Valid \\
\hline 2. & Motivasi Kekuasaan & 1 & 0,477 & 0,312 & Valid \\
& & 2 & 0,108 & 0,312 & Tidak Valid \\
& 3 & 0,584 & 0,312 & Valid \\
& 4 & 0,590 & 0,312 & Valid \\
& & 0,641 & 0,312 & Valid \\
\hline 3. & Motivasi Afiliasi & 1 & 0,757 & 0,312 & Valid \\
& & 2 & 0,516 & 0,312 & Valid \\
& & 3 & 0,717 & 0,312 & Valid \\
& & 4 & $-0,738$ & 0,312 & Valid \\
& & 5 & 0,278 & 0,312 & Tidak Valid \\
\hline 4. & Motivasi Prestasi & 1 & 0,350 & 0,312 & Tidak Valid \\
\hline & 2 & 0,511 & 0,312 & Valid \\
& & 3 & 0,377 & 0,312 & Valid \\
& & 4 & 0,663 & 0,312 & Valid \\
& & 5 & 0,436 & 0,312 & Valid \\
\hline
\end{tabular}


Sumber : Hasil Pengolahan Data Primer (2017).

Tabel 2. Hasil pengujian reliabilitas kuesioner penelitian

\begin{tabular}{ccccc}
\hline No. & Variabel & Indikator & Alpha & Keterangan \\
\hline 1. & Perilaku Kerja & 1 & 0,874 & Reliabel \\
& & 2 & 0,873 & Reliabel \\
& & 3 & 0,874 & Reliabel \\
& & 4 & 0,865 & Reliabel \\
\hline 2. & Motivasi Kekuasaan & 5 & 0,871 & Reliabel \\
& & 2 & 0,879 & Reliabel \\
& & 3 & 0,866 & Reliabel \\
& & 4 & 0,867 & Reliabel \\
& & 5 & 0,864 & Reliabel \\
\hline 3. & Motivasi Afiliasi & 1 & 0,858 & Reliabel \\
& & 2 & 0,869 & Reliabel \\
& & 3 & 0,860 & Reliabel \\
& & 4 & 0,859 & Reliabel \\
& & 5 & 0,883 & Reliabel \\
\hline 4. & Motivasi Prestasi & 1 & 0,876 & Reliabel \\
\hline & & 2 & 0,875 & Reliabel \\
& & 3 & 0,873 & Reliabel \\
& & 4 & 0,875 & Reliabel \\
& & 5 & 0,863 & Reliabel \\
\hline
\end{tabular}

Sumber: Hasil Pengolahan Data Primer (2017).

\section{Uji Hipotesis}

Dari analisis data yang telah dilakukan menggunakan SPSS 23 muncul persamaan analisis regresi berganda sebagai berikut : $\mathrm{Y}$ $=12,377-0,047 \mathrm{X}_{1}+0,351 \mathrm{X}_{2}+0,331 \mathrm{X}_{3}+\mathrm{ei}$

Tabel 3. Hasil analisis pengaruh simultan variabel motivasi terhadap perilaku kerja petani karet Di Desa Puain Kanan Kecamatan Tanta Kabupaten Tabalong

\begin{tabular}{lccccc}
\hline \multicolumn{1}{c}{ Model } & Sum of Squares & df & Mean Square & F & Sig. \\
\hline 1 Regression & 49,418 & 3 & 16,473 & 12,470 & \multirow{2}{*}{$000 \mathrm{~b}$} \\
Residual & 47,557 & 36 & 1,321 & & \\
\hline Total & 96,975 & 39 & & & \\
\hline
\end{tabular}

Sumber: Hasil Pengolahan Data Primer (2017).

Tabel 4. Hasil analisis pengaruh parsial variabel motivasi terhadap perilaku kerja petani karet Di Di Desa Puain Kanan Kecamatan Tanta Kabupaten Tabalong

\begin{tabular}{|c|c|c|c|c|c|}
\hline \multirow{2}{*}{ Model } & \multicolumn{2}{|c|}{$\begin{array}{c}\text { Unstandardized } \\
\text { Coefficients }\end{array}$} & \multirow{2}{*}{$\begin{array}{l}\text { Standardized } \\
\text { Coefficients } \\
\text { Beta }\end{array}$} & \multirow[t]{2}{*}{$\mathrm{t}$} & \multirow{2}{*}{ Sig. } \\
\hline & B & Std. Error & & & \\
\hline 1 (Constant) & 12,377 & 2,336 & & 5,297 & 000 \\
\hline Motivasi Kekuasaan &,- 047 & ,088 &,- 100 &,- 535 & ,596 \\
\hline Motivasi Afiliasi & ,351 &, 119 &, 536 & 2,942 & ,006 \\
\hline Motivasi Prestasi &, 331 &, 110 & 397 & 3,005 & ,005 \\
\hline
\end{tabular}

Sumber: Hasil Pengolahan Data Primer (2017). 
Tabel 5. Hasil uji korelasi dan determinasi variabel motivasi terhadap perilaku kerja petani karet Di Desa Puain Kanan Kec. Tanta Kabupaten Tabalong

\begin{tabular}{|c|c|c|c|c|c|c|c|c|c|}
\hline \multirow[b]{2}{*}{ Model } & \multirow[b]{2}{*}{$\mathrm{R}$} & \multirow[b]{2}{*}{$\begin{array}{c}\mathrm{R} \\
\text { Square }\end{array}$} & \multirow[b]{2}{*}{$\begin{array}{l}\text { Adjusted } \\
\text { R Square }\end{array}$} & \multirow{2}{*}{$\begin{array}{l}\text { Std. Error } \\
\text { of the } \\
\text { Estimate }\end{array}$} & \multicolumn{5}{|c|}{ Change Statistics } \\
\hline & & & & & $\begin{array}{c}\text { R Square } \\
\text { Change }\end{array}$ & $\begin{array}{c}\mathrm{F} \\
\text { Change }\end{array}$ & df1 & $\begin{array}{c}\mathrm{df} \\
2\end{array}$ & Sig. F Change \\
\hline 1 &, $714^{\mathrm{a}}$ & ,510 & 469 & 1,149 & 510 & 12,470 & 3 & 36 & ,000 \\
\hline
\end{tabular}

Sumber: Hasil Pengolahan Data Primer (2017).

\section{Pembahasan}

\section{Uji Keampuhan Instrumen}

Berdasarkan Tabel 1 uji validitas kuisioner penelitian diketahui terdapat 3 butir pernyataan yang tidak valid dikarenakan nilai rhitungnya lebih kecil dari $r$ tabel sehingga 3 butir pernyataan tersebut tidak layak digunakan dalam penelitian. Pada Tabel uji reliabilitas semua butir pernyataan dikatakan reliabel dan jika kuesioner digunakan kembali maka hasilnya akan tetap sama.

\section{Uji Hipotesis}

Analisis data pada penelitian ini secara keseluruhan menggunakan aplikasi Statictical Package for Social Sience (SPSS) 23 dengan analisis regresi berganda untuk membuat penelitian ini lebih efektif dan efisien.

Tabel 3 menunjukan hasil dari pengujian secara simultan. Nilai $F_{\text {hitung }}$ diketahui 12,470 lebih besar dari $F_{\text {tabel }}$ 2,0280 sehingga hipotesis $\mathrm{H}_{0}$ ditolak dan hipotesis $\mathrm{H}_{\mathrm{a}}$ diterima jadi terdapat pengaruh yang signifikan secara simultan (bersama-sama) antara motivasi kekuasaan, motivasi afiliasi dan motivasi prestasi terhadap perilaku kerja petani karet.

Hasil uji t yang telah dilakukan pada ketiga variabel motivasi yaitu variabel motivasi kekuasaan, motivasi afiliasi dan motivasi prestasi diketahui nilai thitung yang paling besar terdapat pada variabel motivasi prestasi yaitu sebesar 3,005. Hal ini menunjukan dari ketiga variabel tersebut variabel motivasi prestasi merupakan motivasi terbesar petani karet dalam menjalankan usahanya.
Berdasarkan Tabel 5 diperoleh koefisien korelasi $(\mathrm{R})$ sebesar 0,714 hal ini menunjukan terdapat hubungan positif antara motivasi kekuasaan, motivasi afiliasi dan motivasi prestasi terhadap perilaku kerja petani karet, karena nilai koefisien korelasi mendekati +1 . Artinya variabel motivasi sangat baik terhadap perilaku kerja petani karet.

Dari analisis tersebut diperoleh hasil koefisien determinasi $\left(\mathrm{R}_{2}\right)$ sebesar 0,510 . Hal ini menunjukan 0,510 atau $51 \%$ kontribusi yang disebabkan oleh motivasi kekuasaan, motivasi afiliasi dan motivasi prestasi terhadap perilaku kerja petani karet, sedangkan $49 \%$ disebabkan oleh faktor lain yang tidak diteliti.

\section{KESIMPULAN}

Motivasi memberikan pengaruh terhadap perilaku kerja petani karet di Desa Puain Kanan Kecamatan Tanta Kabupaten Tabalong dengan nilai $F_{\text {hitung }}$ senilai 12,470 lebih besar dari $F_{\text {tabel }}$ yaitu 2,87. Variabel motivasi yang ada yaitu motivasi kekuasaan, motivasi afiliasi dan motivasi prestasi yang paling memberikan motivasi terbesar terhadap perilaku kerja petani karet di Desa Puain Kanan Kecamatan Tanta Kabupaten Tabalong adalah motivasi prestasi dengan nilai nilai

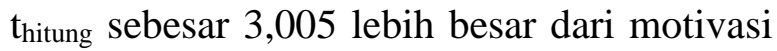
kekuasaan dengan nilai thitung sebesar - 0,535 dan motivasi afiliasi dengan nilai $t_{\text {hitung }}$ sebesar 2,942. Motivasi kekuasaan, motivasi afiliasi dan motivasi prestasi memiliki hubungan positif terhadap perilaku kerja petani karet di Desa Puain Kanan Kecamatan Tanta Kabupaten Tabalong dengan kontribusi variabel motivasi sebesar $51 \%$. 


\section{DAFTAR PUSTAKA}

Badan Pusat Statistik. 2015. Tabalong Dalam Angka. BPS: Tabalong.

Siregar, S. 2013. Metode Penelitian Kuantitatif. PT. Fajar Interpratama Mandiri: Jakarta.

Sugiyono. 2012. Metode Penelitian Bisnis. Alfabeta: Bandung.

Suliyanto. 2011. Ekonometrika Terapan. Penerbit Andi: Yogyakarta.

Tika, M. P. 2006. Metode Riset Bisnis. Bumi Aksara: Jakarta. 